\title{
Ageing in Asia
}

\section{Edmond Chiu}

Population Ageing will have its greatest impact in the developing world, particularly in the Asian region, with a lower level of "ageing preparedness" to meet this challenge. Each country in this region has traditional and new ways to deliver health and social care for its elderly citizens. For people beyond these countries, ignorance, old perceptions and misunderstanding may colour their views of ageing in these countries.

Therefore, Ageing International plans to, with each issue, commission a paper from a country in the region to inform our readership of the challenges and how they are being met and what plans are in place to increase the country's preparedness in the face of population ageing.

The first paper in this series comes from India, a country with rapid population growth as well as a fast growing economy and increasing life expectancy. Future issues will see papers commissioned from China, Japan and Indonesia.

Ageing International hopes these papers will open a window through which readers will see and understand ageing in these countries as described by them.

E. Chiu $(\square)$

University of Melbourne, Victoria, Austrailia

e-mail: Chiu@svhm.org.au 